\title{
Adaptive Sliding Mode Control based on the Fuzzy Theory for Food Processing Robot
}

\author{
Yanni Mao1 \\ Department of Food Science and Engineering, Yantai \\ Nanshan University, Longkou 265713, China \\ e-mail: zhenxiguangyin@163.com
}

\begin{abstract}
Due to the large consumption and dispersed processing of food, therefore, the study of food processing robots have been widely concerned. The food processing robot control system is susceptible to the extreme dynamic characteristics and the influence of external disturbance parameters. Combining fuzzy theory with sliding mode control, Adaptive sliding mode control is proposed based on the theory of fuzzy, in order to improve control accuracy and stability. The simulation results show that compared with the conventional sliding mode control method, the control is not only the external disturbance and parameter perturbation with stronger adaptability and robustness, but also has fast dynamic response and good tracking performance.
\end{abstract}

Key words-Food processing; fuzzy theory; adaptive sliding mode control; robustness

\section{INTRODUCTION}

The construction industry as a pillar industry of the national economy has an very important role in the coordinated operation of the national economy.The rapid development of construction industry to strengthen the urban and rural infrastructure construction, promote the urbanization process, build a harmonious society and improve the efficiency of production in the whole society is of great significance[1]. As the pillar industry of national economy, the status of the construction industry in the national economy become to strengthen little by little, construction promoting the economic development is increasingly significant, there is a mutual influence, mutual promotion and mutual restriction relationship between them.

In recent years, with the continuous improvement of people's living standards, food safety problem get more and more attention of people. The latest achievements of the studies on the food safety continue to spring up. Based on the cloud computing, Miaochao Chen et al. set up a food safety tracking system in 2013. For controlling the food from the production, processing, packaging, circulation links, good results have been achieved. However, the establishment of the platform needs government to vigorously investment and regulation. For developing countries, it is relatively difficult. The platform is developed based on the Android system. The android system belongs to open system. Once being attacked by hackers, therefore, it is easy to modify the platform data recorded by the food. It has certain security hidden danger. On the other hand, because the food has big consumption and processing disperse, it is difficult to monitor the food safety. On the premise of saving

\author{
Wenshui Xia2 \\ The School of Food Science and Technology, Jiangnan \\ University, Wuxi 214122, China \\ e-mail:
}

manpower, food processing robot can avoid the pollution of food processing. Therefore, for food processing research of the robot get more and more attention.

When food processing robot running in the processing of unstructured environment, due to the fuselage elastic deformation, parameter variations and external disturbances, it makes the established motion model highly nonlinear, strong coupling and uncertainty. It affects the control quality of the controller(1-2). So in the control system under the condition of uncertainty and unknown disturbance, it guarantees the stability of control system to realize tracking control. The practical application of tracked robot is particularly important. There is less food processing robot motion control method in the existing literature. Food processing robot and wheeled mobile robot has many similarities in kinematics model. Direct reference of wheeled robot control is difficult to meet the requirements of tracked robot precise control.

Sliding mode control is a kind of control method. The fundamental difference between with conventional control is the control discontinuity, which makes the system a "structure" changing with the switch characteristics. In this paper, the food processing robot fuzzy sliding mode control is proposed. The fuzzy theory is combined with sliding mode control. The total control is built by the equivalent control and switch control. The equivalent control of approximation control is designed. It adjusts the control parameters of the adaptive law and adjusts the output control in real time. It aims to make the control object along the designed "sliding mode" trajectory.

\section{THE DESIGN OF SLIDING MODE CONTROLLER}

The sliding surface is defined as

$$
s=c[R(k)-x(k)]=0
$$

The $\mathrm{C}$ conforms the stability condition of sliding mode

$$
C=\left[C_{1} C_{2} \ldots C_{n}\right], C_{n}=1
$$

Assume

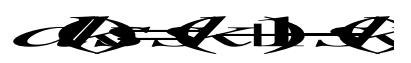

According to exponential reaching law

$$
\begin{aligned}
& d s(k)=-\varepsilon T \operatorname{sgn}(s(k))-q T s(k), \\
& \varepsilon>0, q>0,1-q T>0
\end{aligned}
$$


So the sliding mode controller based on exponential approach law is as follows.
The system structure of double adaptive fuzzy sliding mode control is shown in Fig .1.

$$
\begin{aligned}
& u(k)=(C B)^{-1}[C(R(k+1)-R(k)) \\
& -C(A-1) x(k)-d s(k)]
\end{aligned}
$$

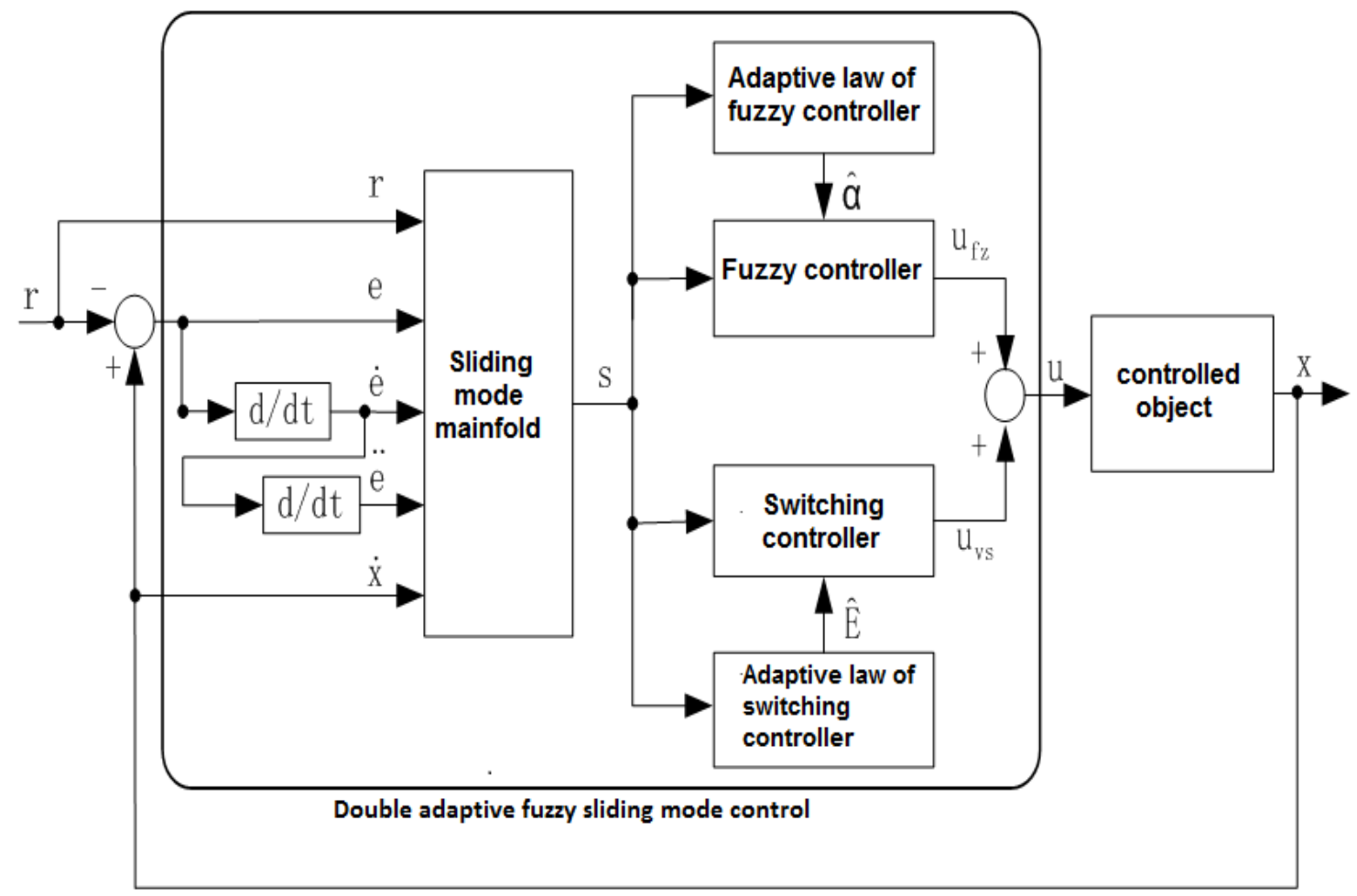

Figure 1. Double adaptive fuzzy sliding mode control system

III. STABILITY ANALYSIS

Define the Lyapunov function is:

$$
V(k)=\frac{1}{2}[S(k)]^{2}
$$

So

$$
\begin{aligned}
& V(k)=\frac{1}{2}[S(k)]^{2} \\
& V(k+1)=\frac{1}{2}[S(k+1)]^{2} \\
& V(k+1)-V(k) \\
& =\frac{1}{2}[S(k+1)]^{2}-\frac{1}{2}[S(k)]^{2} \\
& =\frac{1}{2}\{[S(k+1)-S(k)][S(k+1)+S(k)]\}
\end{aligned}
$$

$$
\begin{aligned}
& V(k)=\frac{1}{2}[S(k)]^{2} \\
& V(k+1)=\frac{1}{2}[S(k+1)]^{2}
\end{aligned}
$$

$\because[S(k+1)+S(k)] \operatorname{sgn}(S(k))$

$=\left[-q T S(k)-\frac{|S(k)|}{2} T \tan \operatorname{sig}(\|x\|) \operatorname{sgn}(S(k))\right] \operatorname{sgn}(S(k))$

$=-(q+0.5 \tan \operatorname{sig}(\|x\|)) T|S(k)|<0$

$\because[S(k+1)-S(k)] \operatorname{sgn}(S(k))$

$\left.=\left(2-q T S(k)-\frac{|S(k)|}{2} T \tan \operatorname{sig}(\|x\|)\right) \operatorname{sgn}(S(k))\right] \operatorname{sgn}(S(k))$

$=(2-q T-0.5 T \tan \operatorname{sig}(\|x\|))(S(k))$

$=(2-q T-0.5 T)|S(k)|>0$

For the former case, the following equation can be obtained: 
$V(k+1)-V(k)$

$=\frac{1}{2}\{[(S(k+1)]-S(k)) \operatorname{sgn}(S(k))]$

$[S(k+1)+S(k)) \operatorname{sgn}(S(k))]\}$

$\therefore V(k+1)-V(k)<0$

$\therefore V(k+1)<V(k)$
Therefore, the adaptive sliding mode control system is stable.

\section{NUMERICAL SIMULATION}

In order to verify the validity of the algorithm, the food processing robot is studied by numerical simulation using MATLAB (omitted parameters), the simulation results $\begin{array}{llllll}\text { shown in } & \text { Fig } & .2 & \text { to } & \text { Fig } & \end{array}$

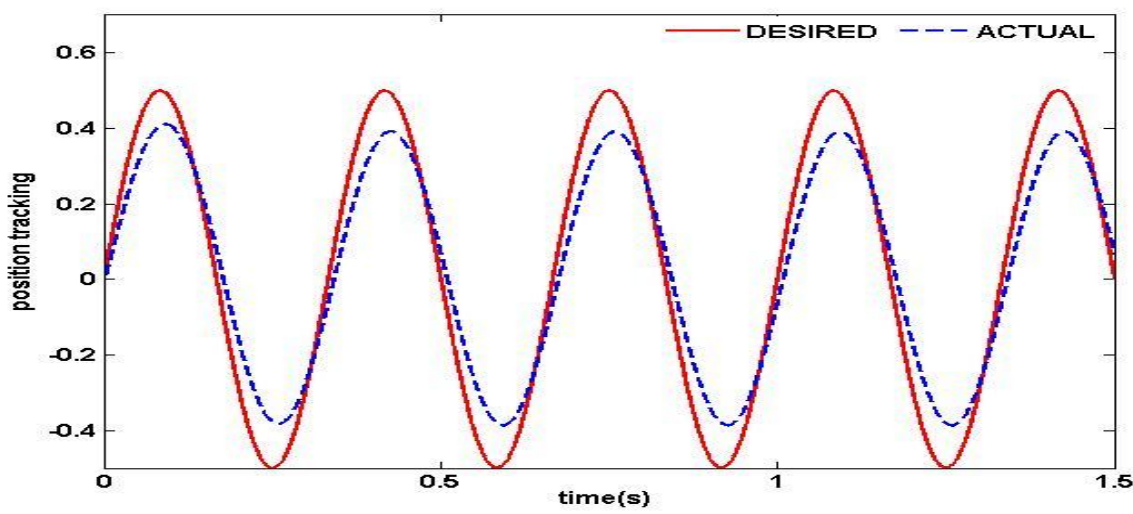

Figure 2. Traditional sliding mode position tracking

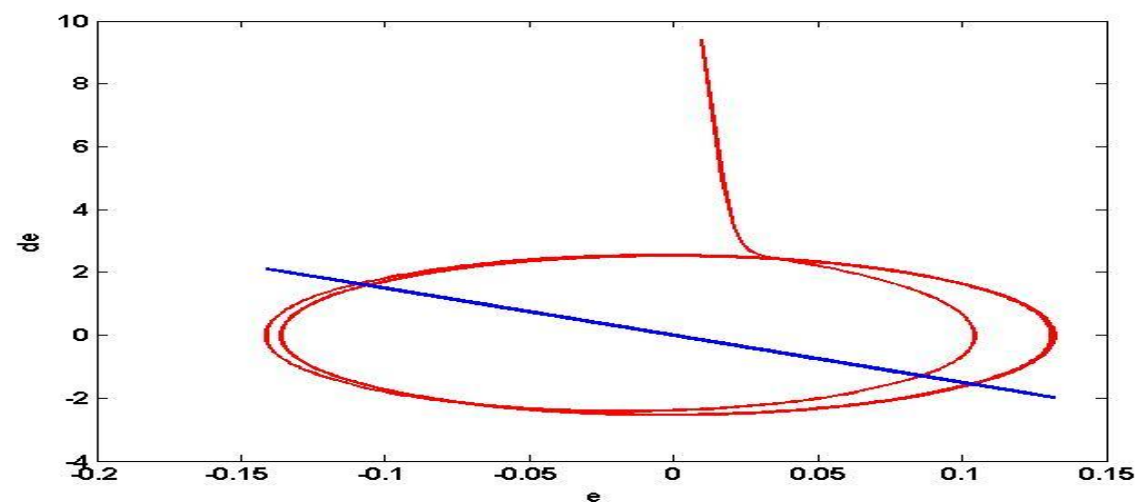

Figure 3. Traditional sliding mode trajectories

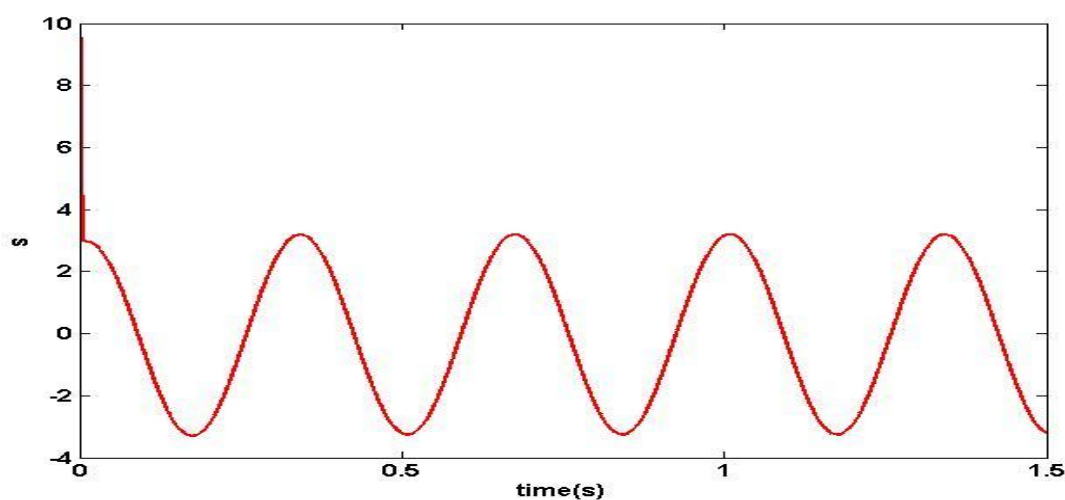

Figure 4. Traditional sliding sliding surface 


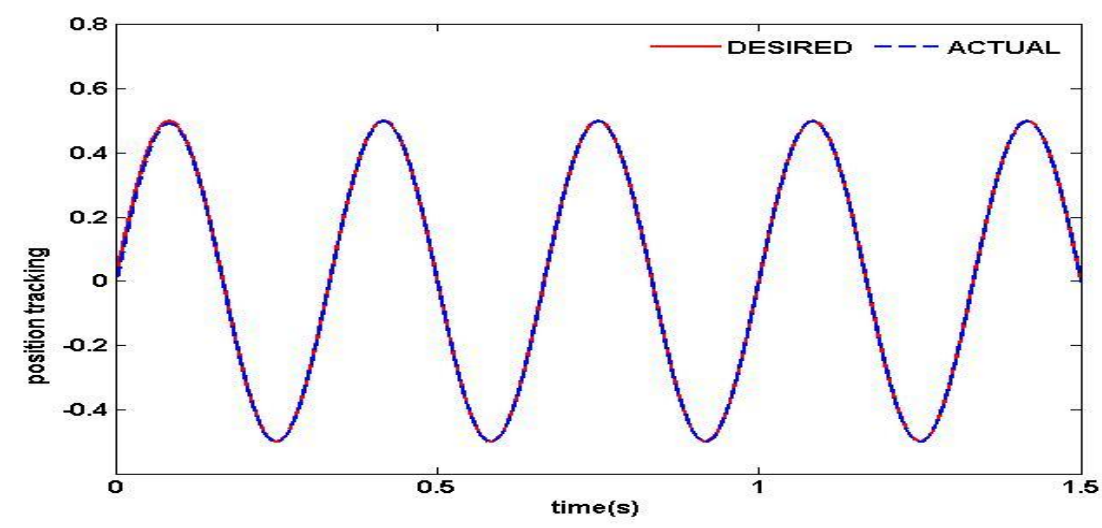

Figure 5. Adaptive Sliding Mode sliding position tracking

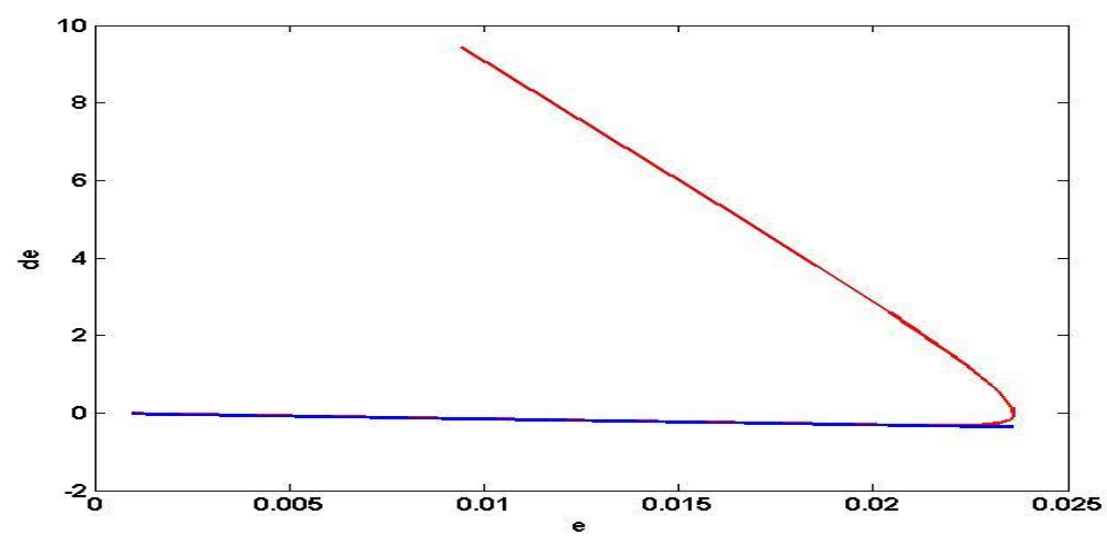

Figure 6. Adaptive Sliding Mode sliding phase trajectory

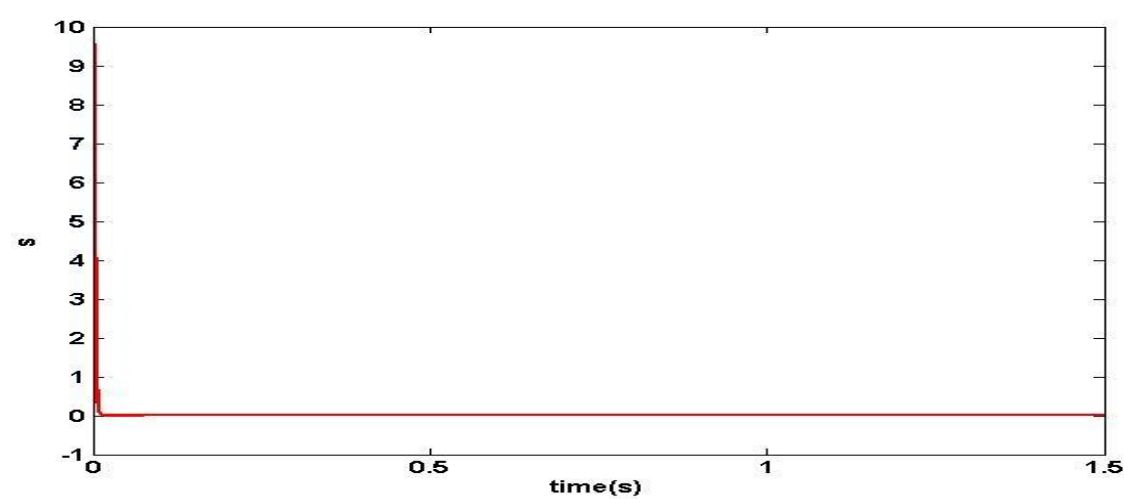

Figure 7. Adaptive Sliding Mode sliding surface

\section{CONCLUSION}

The above simulation results shows that the paper designed the food processing robot is adopted adaptive sliding mode control. It is not easily affected by the extreme dynamic parameters and external disturbance. The food processing robot has a good stability, quickness and resistance to disturbance. So it has high project application values.

\section{ACKNOWLEDGMENT}

This paper is supported by the foundation of domestic visiting scholar project funding of higher schools in Shandong province for young backbone teachers.

\section{REFERENCES}

[1] M.C.Chen, X.S. Kong, C. Kan.Application of Statistical Analysis Software in Food Scientific Modeling[J].Advance Journal of Food Science and Technology,2014,6(10):1143-1146.

[2] F.H.Zhang, Y.L. Fu, S.G. Wang. Adaptive Control of Free-floating Space Robot with Inertia Parameter Uncertainties[J].Acta Aeronautica et Astronautica Sinica,2012,33(12):2347-2354. 
[3] J.K. Liu,F.C. Sun.Research and development on theory and algorithms of sliding mode control[J].Control Theory \& Applications,2007,24(3):407-418,

[4] J.Y. Yang, Y.F. Cui, M.C. Chen. Sliding Mode Control Based on RBF Neural Network for Parallel Machine Tool[J].The Open Automation and Control Systems Journal,2014(6):575-582.

[5] H.L. He, W.C. He,W.G. Liu,L.Y. Feng.Tracking Control of Robot Using Hybrid Controller Based on Neural Network and Computed Torque[J].Transactions of the Chinese Society of Agricultural Machinery,2013,44(5):270-275.

[6] Y.Zhao, H. Xu, M.C. Chen. Research and Development of Cloudbased Food Safety Traceability System[J].Advance Journal of Food Science and Technology, 2013,5(12):1580-1583.
[7] J.Jiao, W.W.Chen. Intelligent variable structure control for automated guided vehicle[C],IEEE World Congress on Evolutionary Computation, 2008,pp.3968-3973.

[8] J.L.Zhou,W.H. Zhang.Robust optimal control for robotic manipulator[J].Computer Engineering and Applications,2007,43(8):168-170,173.

[9] M.X.Sun,H Wang. Switching function dynamics design for uncertain variable structure systems with repetitive control[J].International Journal of Control, 2011,84(7):1196-1208.

[10] X.J. Liu,R. Hen. Sliding mode control in electromagnetic hydraulic hybrid anti lock braking system[J].Transactions of the Chinese Society for Agricultural Machinery,2014,45(5):1-7.

[11] J.D. Han,D.L. Tan,X.S. JIANG.Joint acceleration feedback control for direct-drive robot decoupling[J].Acta Automatica Sinica, 2000,26(3):289-295. 